\title{
LAS EXPOSICIONES NACIONALES DE COSTA RICA 1917 Y $1918^{1}$
}

\section{COSTA RICAN NATIONAL EXHIBITIONS 1917-1918}

\author{
Chester Urbina Gaitán*
}

RESUMEN

Las Exposiciones Nacionales de 1917 y 1918 fueron utilizadas por el régimen de Federico Tinoco para hacer una buena imagen política al presentar a Costa Rica como un país agrícola, pacífico y educado. La figura política más premiada en las obras artísticas de estos certámenes fue la del Lic. Mauro Fernández, debido al interés de la dictadura tinoquista por tratar de salir de la crisis política en que se encontraba inmersa.

PALABRAS CLAVE: COSTA RICA * FEDERICO TINOCO * EXPOSICIONES * ESTADO * IDENTIDAD * EDUCACIÓN

\section{ABSTRACT}

The National Exhibitions of 1917 and 1918 were used by FedericoTinoco regime to make good political image for to present at Costa Rica as an agricultural country, peaceful and polite. The political most awarded figure in the artistic works of these events was Mr. Mauro Fernandez, due to the interest of the dictatorship tinoquista for try to overcome of the political crisis in which it was immersed.

KEYWORDS: COSTA RICA * FEDERICO TINOCO * EXHIBITIONS * STATE * IDENTITY * EDUCATION

$1 \quad$ El autor agradece al Dr. Rafael Cuevas Molina por los comentarios a una versión preliminar de este texto. 


\section{INTRODUCCIÓN}

Hacia finales del siglo XIX, los intelectuales y políticos costarricenses al servicio del Estado, se interesaron en la formulación y presentación de una raza homogénea, blanca y de origen europeo, donde las raíces españolas se ponen como las originarias. La educación escolar desempeñó un papel fundamental en la transmisión e identificación del costarricense con esta imagen racial (Taracena y Piel, 1995: 75-85; Revista de Ciencias Sociales, 1998: 31-53), la que se elaboró dentro del marco de estructuración y articulación de un proyecto de nación cultural y una identidad nacional (Molina $y$ Palmer, 1992: 189-198). El mismo artífice de la reforma educativa de los liberales positivistas, el Lic. Mauro Fernández hace referencia en su Memoria de Educación en 1885, a una raza homogénea (Taracena y Piel, 1995: 77). En la década de 1910 y 1920, la imagen de la Costa Rica blanca será acogida entre los círculos de obreros y artesanos citadinos, los cuales se opondrán a la llegada de trabajadores extranjeros, porque consideraban que les producían competencia en sus puestos de trabajo (Taracena y Piel, 1995: 63-74).

La intelectualidad costarricense abordaba el tema de lo aborigen en términos arqueológicos y museográficos, amén de manifestar desdén por las poblaciones que no compartían el mismo acervo cultural del Valle Central, como la guanacasteca, que estaba más emparentada con la nicaragüense a un nivel cultural (Vínculos, 1997: 99-123; Molina y Enríquez, 2000: 335-356). En este sentido, las exposiciones de artes plásticas en Costa Rica, durante el período 1928-1937, promovieron la transmisión de un sentimiento de pertenencia nacional a través de las pinturas que se presentaron durante estos años (Zavaleta, 2004).

A principios del siglo xx, la nueva intelectualidad costarricense impugnó el modelo educativo liberal, tratando de contribuir a que el pueblo y las clases trabajadoras, en particular, fueran críticas de sí mismas y de lo que interesadamente se les enseñaba. Debido a que esta nueva intelectualidad procuraba que la escuela desempeñara un papel fundamental en la renovación de las costumbres, fomentando en el alumno el espíritu crítico y la búsqueda de medios para la construcción de una sociedad más democrática, esto le valió la crítica de los sectores conservadores de la oligarquía y en particular, del clero (Morales, 1993: 160 y 175; Molina, 2001).

Roberto Brenes Mesén fue uno de estos intelectuales $y$ desde su puesto de Ministro de Educación (1917-1918), promovió su propuesta educativa para escuelas y colegios del país. Trató de convertir la escuela en un taller de forja de un hombre más completo, más rico espiritualmente $y$ más productivo en el trabajo y en la economía del país (Dengo, 2002: 65). Sin embargo, Brenes Mesén al igual que otros compañeros de generación como Joaquín García Monge, José María Zeledón, Omar Dengo y Carmen Lyra, empezaron a moderar sus puntos de vista a medida que comenzaron a ascender en términos sociales e institucionales, con excepción de la última persona mencionada (Molina, 2009: 75).

Brenes Mesén se percató de la necesidad de un cambio en el sistema educativo de Costa Rica y manifestó su inconformidad con las reformas implantadas en el país por Mauro Fernández, las cuales eran el resultado de un planteamiento liberal destinado a ratificar el pensamiento liberal-positivista de épocas anteriores, mientras que él deseaba experimentar con nuevas ideas generadas en parte durante su estadía en Chile, como también por haber pasado por un proceso de cambios en su experiencia personal (Herencia, 2009: 14-15).

Con respecto al gobierno de Federico Tinoco Granados, se tiene que estuvo en el poder de 1917 a 1919, siendo uno de los más funestos en la historia nacional debido a su pésima política monetaria y fiscal, a su falta de escrúpulos y al despotismo empleado (Oconitrillo, 1980: 41 y Murillo, 1981). Por todo lo anterior, el presente artículo pretende estudiar cómo el gobierno de Federico Tinoco Granados (1917-1919), utilizó las Exposiciones Nacionales de 1917 y 1918 para hacer una buena imagen política. 
TRABAJO, EDUCACIÓN Y RAZA BLANCA LAS EXPOSICIONES NACIONALES DE 1917 Y 1918

Para 1917, el Presidente de Costa Rica, Federico Tinoco Granados señalaba que el sistema de exposiciones nacionales públicas debían constituir un homenaje patriótico a la existencia del Estado, simbolizada en el aniversario de su independencia política, por ser el trabajo una de las más altas manifestaciones del verdadero civismo y a la que la comunidad debía a su vez, consagrar atención preferente, rodeándola del prestigio que merecía (Exposición Nacional del 15 de setiembre de 1917, 1918: 3).

Este $y$ otros motivos lo llevaron a decretar la realización de la Exposición Nacional, la cual se llevaría a cabo el día 15 de setiembre del año 1917. Sobre el festejo del 15 de setiembre se conoce que durante la Administración del Lic. Alfredo González Flores (1914-1917) se consagra la fiesta escolar de esta fecha patria. A partir de 1915, comenzó una suplantación sistemática de los militares por escolares en todas las actividades del 15 de setiembre. La fiesta escolar comenzó a ser parte de la imagen de la nación costarricense que fortalecía el pacifismo del país: un país con más maestros que soldados. Para 1915, Justo A. Facio, el Jefe Técnico y Administrativo de Instrucción Pública, señalaba que los inspectores escolares recibieron la orden que durante los seis días anteriores al 15 de setiembre, las escuelas debían dedicarse a fomentar el sentimiento de la patria en el niño, por medio de la figura de los personajes que más eficazmente han servido a la patria, como Juan Mora Fernández, Juan Rafael Mora Porras y Juan Santamaría, por medio de lecturas, poesías, relaciones, etc. Debido a la labor que involucraban estos actos, el día siguiente a la celebración del 15 de setiembre, sería considerado como asueto en todas las escuelas de la República (Díaz, 2008 y 2006: 18-19).

Luego de que Tinoco declarara la realización de la Exposición Nacional, pasó a nombrar la Junta Directiva de este certamen, cuyos miembros fueron los destacados científicos e intelectuales vinculados al aparato educativo, al Museo Nacional y al trabajo arqueológico: Anastasio Alfaro, Rafael Alvarado González, Enrique Ortiz, Fidel Tristán y Enrique Cappella. La inauguración del evento se efectuó en el edificio Juan Rafael Mora Porras - el cual estaba ubicado donde actualmente se localiza el Teatro Mélico Salazar - a las 9: 30 am (Exposición Nacional del 15 de setiembre de 1917, 1918: 9 y 13). En la inauguración se destacó la presencia del Presidente Tinoco Granados y del Obispo de Costa Rica, Monseñor Juan Gaspar Stork. El programa de apertura estaba compuesto de los siguientes eventos:

1. Música del Himno Nacional

2. Discurso del Ministro de Fomento Gral. Juan Bautista Quirós

3. Canto del Himno a la Bandera de Costa Rica por los alumnos de los grados superiores de las escuelas participantes

4. Discurso del Ministro de Instrucción Pública profesor Roberto Brenes Mesén

5. Canto del Himno del 15 de setiembre por los alumnos antes mencionados

6. Motivos de la Exposición por el profesor J. Fidel Tristán

7. Canto del Himno Nacional 


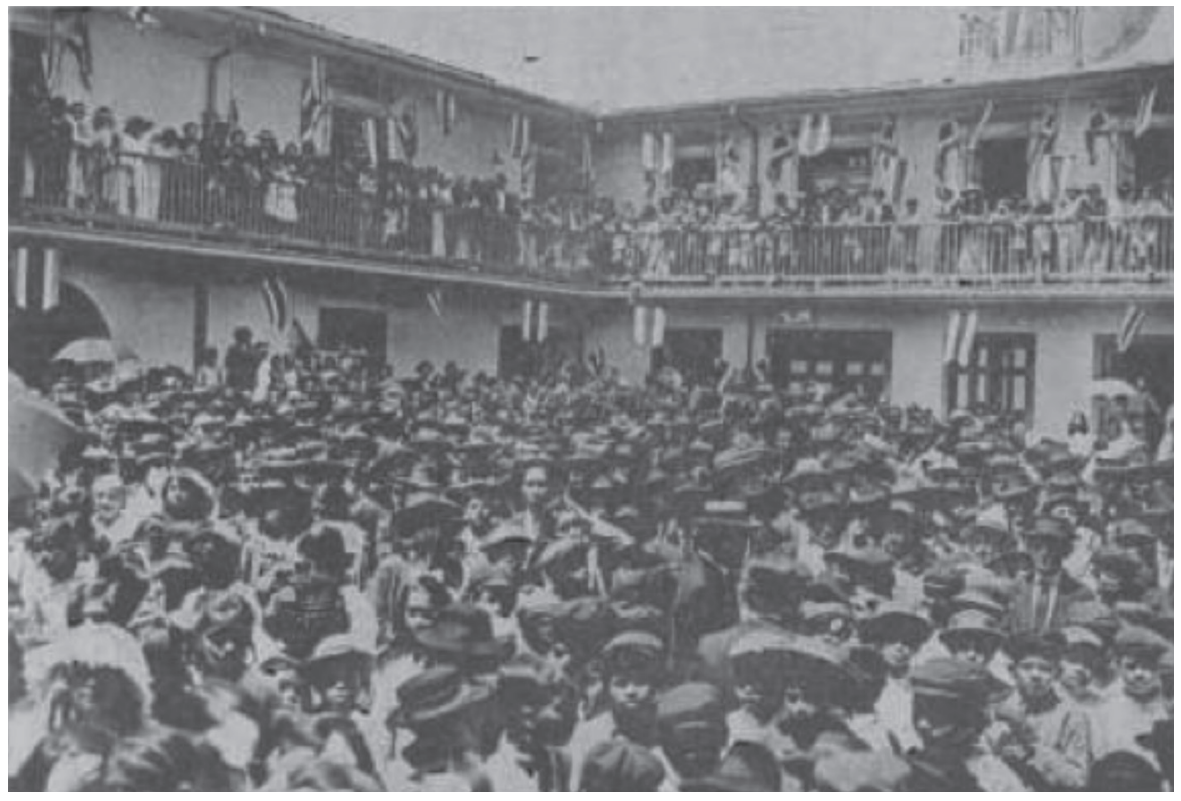

FOTOGRAFÍA 1

EXPOSICIÓN NACIONAL DE 1917

EDIFICIO JUAN RAFAEL MORA PORRAS DURANTE EL ACTO INAUGURAL

El Gral. Quirós en su discurso resaltaba el valor del trabajo:

Los directores de la enseñanza han creído conveniente que los escolares cooperen en este movimiento generoso en el cual ha de recibir el trabajo la unánime consagración de nuestros aplausos y recompensas, la grata voz de aliento que merece como fuente viva de la prosperidad nacional; y resulta hermoso en verdad, el espectáculo que nos presenta en estos momentos la feliz conjunción de las fuerzas del hombre y del niño en el más austero altar de la Patria, como testimonio de la realidad de hoy, como halagadora promesa del futuro engrandecimiento y como símbolo, a la vez, de la indestructible solidaridad de las generaciones humanas (ibíd.: 17-18).

La referencia a la laboriosidad de los costarricenses no era nada nuevo en el país, pues el bachiller Rafael Francisco Osejo exaltaba en 1834, la estabilidad política y la permanencia del sistema constitucional de gobierno. Acerca de los habitantes decía que eran "pacíficos y laboriosos" (Zelaya, 1971: 80). Esta imagen nacional se consolidó en las últimas décadas del siglo XIX. Joaquín Bernardo Calvo en sus Apuntamientos geográficos, estadísticos e históricos de la República de Costa Rica (1887), hace referencia a que la "raza nacional" era blanca, homogénea, sana $y$ robusta, $y$ unida a estas buenas condiciones físicas se encontraban las de la laboriosidad, su afán por la cultura y prosperidad y su espíritu de orden y amor al trabajo (Calvo, 1887: 34; Revista Estudios, 2003: 73-104).

Por su parte, el educador Brenes Mesén exaltaba el papel de la educación en la protección de la trayectoria histórica nacional:

Las miradas contemplativas descubrirán en la exposición de las escuelas como el nacimiento de una nueva institución, la escuela de un próximo porvenir en la cual convivirán los anhelos de la cultura espiritual y las actividades industriales que crearan un nuevo tipo del costarricense, más apto para comprender los 
trascendentales problemas que le impone su ventajosa posición geográfica en el mundo, y más resuelto y mejor preparado para defenderla como un sagrado patrimonio de sus mayores (Exposición Nacional del 15 de setiembre de 1917, 1918: 19).

Fidel Tristán en su discurso alababa la fecha del 15 de setiembre y la defensa de la patria:
Quiera el destino que esta Exposición marque una nueva era de prosperidad $y$ de progreso y que sea el 15 de setiembre de cada año la fecha gloriosa que nos recuerda que en nuestras manos está mantener la tierra que nos legaron nuestros antepasados, llevando como divisa cada día las hermosas palabras de nuestro Himno Nacional: ¡Bajo el límpido azul de tu cielo, vivan siempre el trabajo y la paz! (ibíd.: 24).

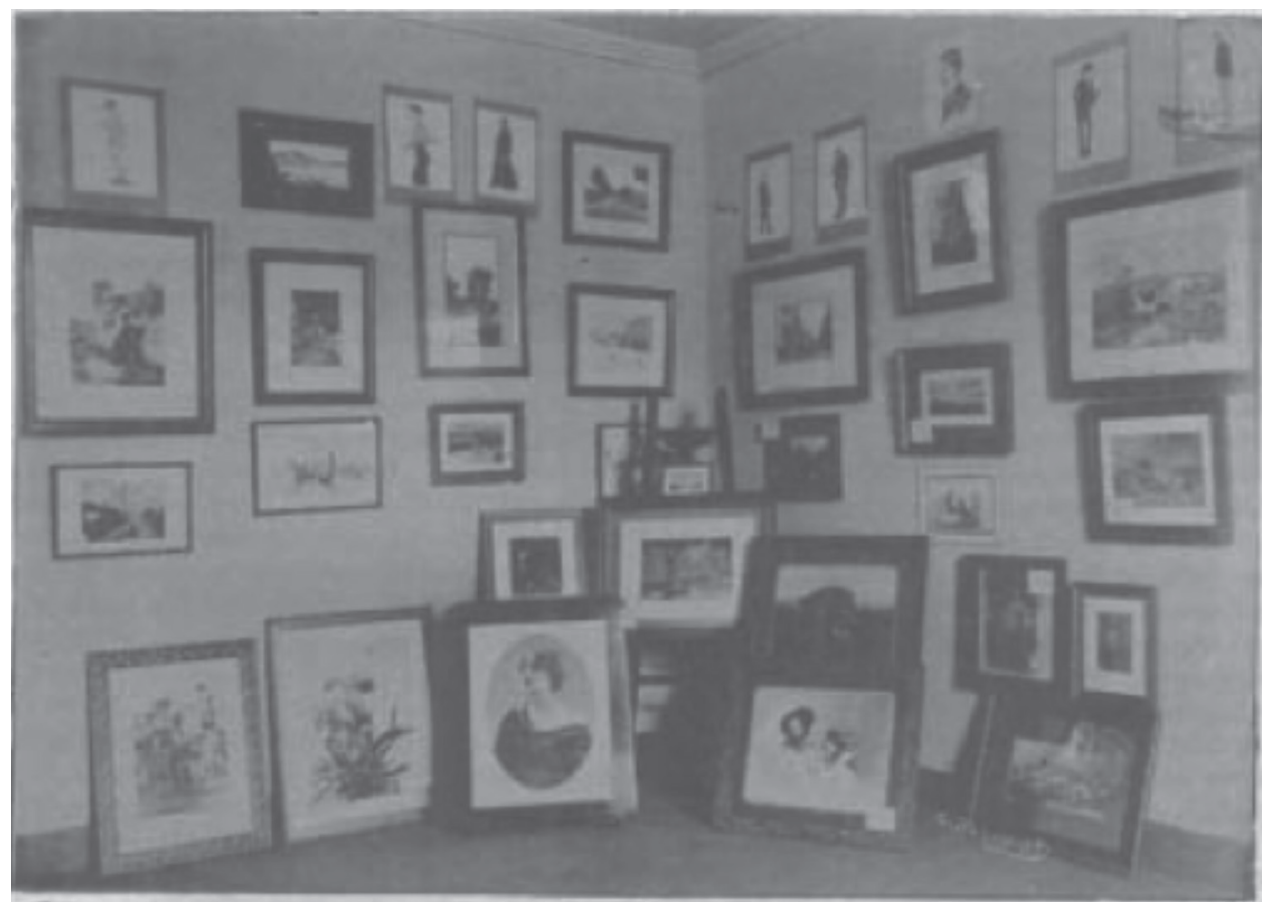

FOTOGRAFÍA 2

UN ÁNGULO DEL SALÓN DE ACUARELAS

Entre los ganadores de la Exposición Nacional de 1917, se destacan: Próspero Calderón por su ampliación al crayón del retrato del Lic. Mauro Fernández; Mateo Fournier y E. Capella por su mapa de Costa Rica; Manuel Gómez Miralles por sus fotografías al aire libre; Francisco Hernández por sus caricaturas de costumbres; Carlos Herrero por sus caricaturas originales de tipos conocidos; Gilberto Huertas por su copia del retrato del Lic. Mauro Fernández; Ramón Arturo por su copia al crayón del retrato del Lic. Mauro Fernández; Sotillo Picornell por sus paisajes artísticos y contraluz, y Carlos Salazar por su Ponche Nacional (ibíd.: 85-93). El hecho de que varios artistas recibieran premios por reproducir el retrato de don Mauro Fernández radica en el interés del gobierno de Tinoco de exaltar a esta figura política, para lo cual develó su estatua en 1918, en el período más agudo de la dictadura tinoquista, en un acto evidente de distracción, legitimación e integración nacional (Díaz, 2006: 
20-21). Cabe destacar que Mauro Fernández fue suegro del Presidente Tinoco Granados. El premiar la elaboración del mapa del país radicó en el interés de los gobernantes de turno para que los costarricenses conocieran la extensión de la comunidad política imaginada (Anderson, 1993: 240-241) y el territorio controlado por el Estado.
El verdadero objetivo de estas exposiciones residía en el interés de Tinoco por hacer buena imagen política. Estos eventos perseguían el mismo objetivo por el cual Costa Rica participó en las exposiciones internacionales de finales del siglo XIX; es decir, el de presentarse como un país agrícola, pacífico y educado (Anuario de Estudios Centroamericanos, 1998: 91).

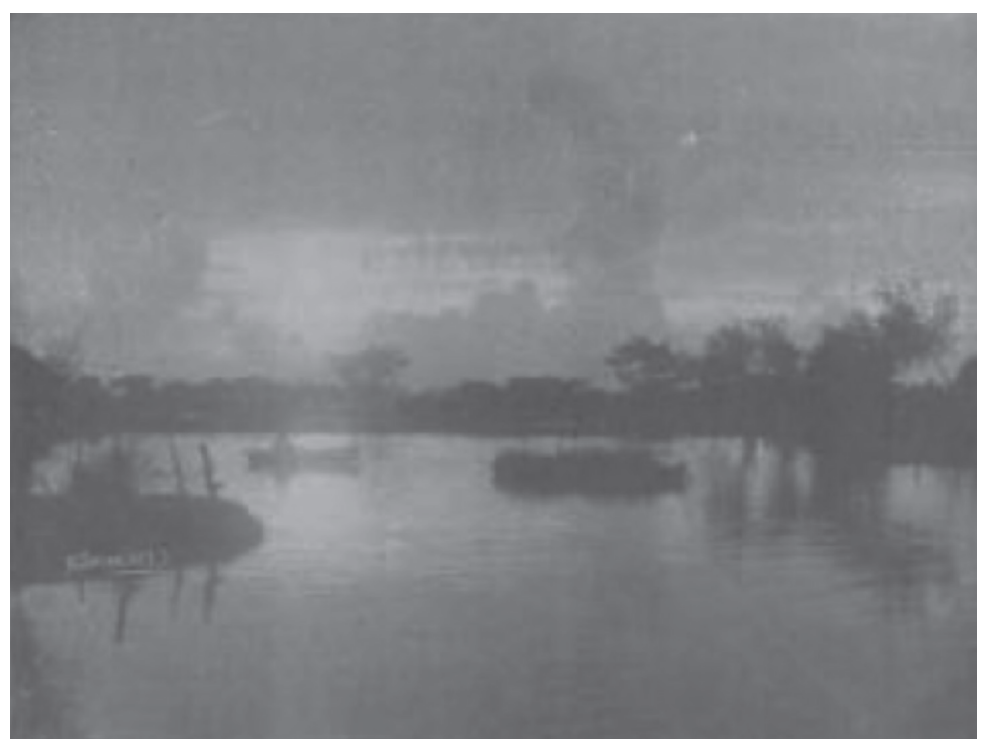

FOTOGRAFÍA 3 PAISAJE JOSEFINO

TOMADA POR SOTILLO PICORNELL Y PREMIADA EN LA EXPOSICIÓN NACIONAL DE 1917

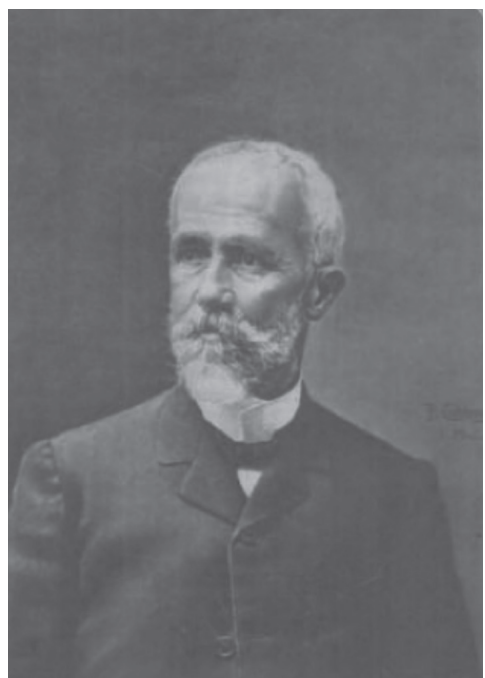

IMAGEN 1

CUADRO DEL LIC. MAURO FERNÁNDEZ REALIZADO POR PRÓSPERO CALDERÓN 
En cuanto a los trabajos literarios ganadores, estos correspondieron a "Mi mejor amigo" de Rodolfo Castaing (León Flordelmar), quien escribió sobre el amor al campo y a la patria; "Antón" de Carlos Jinesta (Puki), el cual trata sobre el campanero de una iglesia y el amor que siente por su madre, $y$ "El caso de él" por Jenaro Valverde L. (Claudio Ethal), donde se resalta cómo un bachiller de secundaria pudo a través de este título llegar a ser diputado (Exposición Nacional del 15 de setiembre de 1917, 1918: 67-80).

Como se menciona anteriormente, en la Exposición Nacional de 1917, se resaltaron las características del ser costarricense como trabajador, educado y perteneciente a una raza homogénea y blanca; no obstante, no se expuso nada referente a sus raíces indígenas, pues estas eran ubicadas antes de la conquista española. Un precedente de esta marginación se encuentra en las exposiciones que organizaba el Museo Nacional, a finales del siglo XIX (Vínculos: 99-123).

En el discurso de clausura de este evento, el Subsecretario de Fomento, Alejandro Aguilar, le dirigía a los estudiantes de escuela las siguientes palabras: “...sin olvidar nunca que el trabajo honra $y$ dignifica, que llegaréis a ser grandes $y$ podréis, con vuestros méritos y virtudes, con vuestra inteligencia y saber, hacer grande también a nuestra patria" (Exposición Nacional del 15 de setiembre de 1917, 1918: 67-80).

En la Exposición Nacional de 1918, participaron pintores que no lo hicieron en el año 1917, destacándose entre ellos don Tomás Povedano, quien exhibió varios cuadros como "Concherías", "Orquídeas", "Muchacho tocando la dulzaina" y "En Febrero". Para Eugenio de Triana, en este último lienzo, don Tomas se había inspirado en la obra "Concherías" de Aquileo J. Echeverría. Asimismo, pese a que varios críticos lo querían descalificar porque parecía un cuadro andaluz por el conjunto de elementos pintados y porque la "conchita" también parecía andaluza, para de Triana que la mujer tuviera un tipo andaluz no lo hace censurable, máxime que una niña costarricense sirvió de modelo, por lo que se debía de estar complacido en ese parecido, ya que constituye un claro testimonio de que Costa Rica ha sabido conservar en sus mujeres el noble abolengo de la madre España. Además, el cuadro presenta los detalles que hacen característico al campesino nacional. La dama que aparece en la pintura estaba con los pies descalzos, desarrollados libremente y estaba en la ruborosa actitud de la mujer tímida que espera (Athenea, 1918: 420).

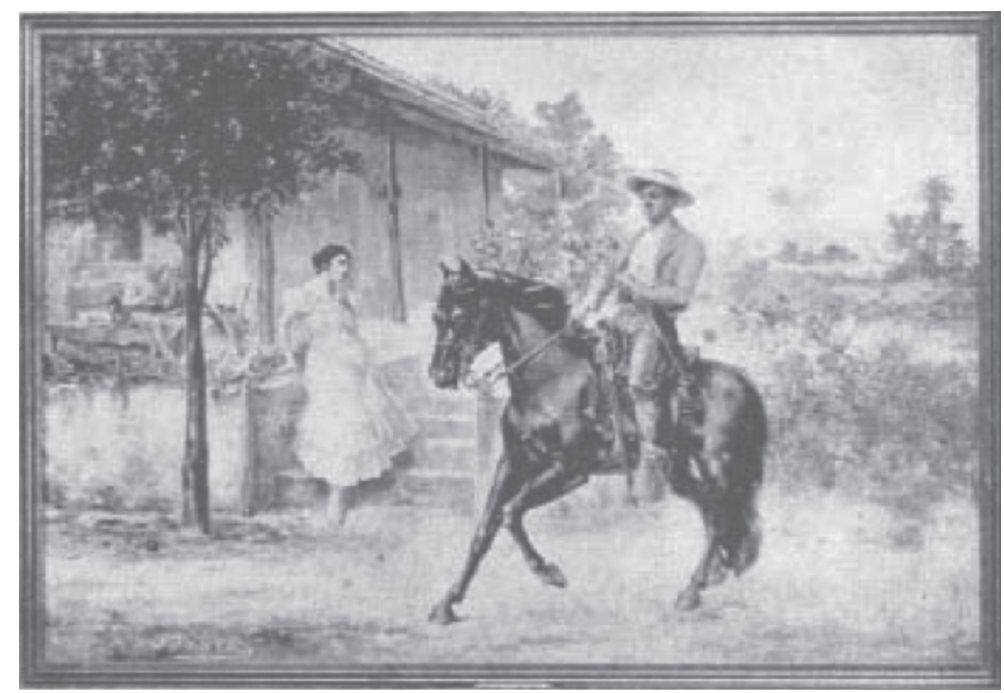

IMAGEN 2

"EN FEBRERO” DE TOMÁS POVEDANO 


\section{CONCLUSIÓN}

Las Exposiciones Nacionales de 1917 y 1918 fueron utilizadas por el régimen de Federico Tinoco para hacer buena imagen política, al presentar a Costa Rica como un país agrícola, pacífico y educado. Esta imagen había sido formulada por los principales intelectuales al servicio del Estado desde finales del siglo XIX — con el fin de establecer el proyecto político-cultural de nación- dándose a conocer al mundo en las exposiciones internacionales. La figura política más premiada en las obras artísticas de estos certámenes fue la del Lic. Mauro Fernández artífice de la Reforma Educativa de 1886- debido al interés de la dictadura tinoquista por trata de salir de la crisis política en que se encontraba inmersa. Al igual que lo venía haciendo el Museo Nacional en la Exposición Nacional de 1917, se resaltaron las características del ser costarricense como trabajador, educado y perteneciente a una raza homogénea y blanca, no se expuso nada referente a sus raíces indígenas, pues estas eran ubicadas antes de la conquista española.

\section{BIBLIOGRAFIA}

\section{FUENTES}

Athenea 6 (II). 15 de octubre. San José: Tip. Trejos Hnos, 1918.

Calvo, Joaquín Bernardo. República de Costa Rica. Apuntamientos geográficos, estadísticos e históricos. San José: Imprenta Nacional, 1887.

Exposición Nacional del 15 de setiembre de 1917. San José: Imprenta Nacional, 1918.

LIBROS

Anderson, Benedict. Comunidades imaginadas. Reflexiones sobre el origen y la difusión del nacionalismo. México DF: Fondo de Cultura Económica, 1993.

Díaz Arias, David. La Fiesta de la Independencia en Costa Rica, 1821-1921. San José: Editorial de la Universidad de Costa Rica, 2008.

Dengo, María Eugenia. Roberto Brenes Mesén. San José: Editorial Universidad Estatal a Distancia, 2002.
Molina, Iván. La ciudad de los monos. Roberto Brenes Mesén, los católicos heredianos y el conflicto cultural de 1907 en Costa Rica. Heredia: EUNA, 2001.

Molina, Iván y Enríquez, Francisco (comps.). Fin de siglo XIX e identidad nacional en México y Centroamérica. Alajuela: Museo Histórico Cultural Juan Santamaría, 2000.

Molina, Iván y Palmer, Steven (eds.). Héroes al gusto y libros de moda. San José y South Woodstock, Vermont: Editorial Porvenir y Plumsock Mesoamerican Studies, 1992.

Morales, Gerardo. Cultura oligárquica y nueva intelectualidad en Costa Rica 1880-1914. Heredia: EUNA, 1993.

Murillo Jiménez, Hugo. Tinoco y los Estados Unidos: génesis y caída de un régimen. San José: Editorial Universidad Estatal a Distancia, 1981.

Oconitrillo García, Eduardo. Los Tinoco (19171919). San José: Editorial Costa Rica, 1980.

Taracena A., Arturo y Piel, Jean. Identidades nacionales y Estado moderno en Centroamérica. San José: Editorial de la Universidad de Costa Rica, 1995.

Zavaleta Ochoa, Eugenia. Las exposiciones de artes plásticas en Costa Rica (1928-1937). San José: Editorial de la Universidad de Costa Rica, 2004.

Zelaya Goodman, Chester J. El bachiller Osejo. Tomo II. San José: Editorial Costa Rica, 1971.

\section{REVISTAS IMPRESAS}

Gólcher, Erika. "Imperios y ferias mundiales: la época liberal". Anuario de Estudios Centroamericanos 24 (1-2). San José: Editorial de la Universidad de Costa Rica, 1998.

Carvajal, María Isabel. "Roberto Brenes Mesen: su visión de la cultura y educación en la Costa Rica de principios del siglo Xx". Herencia 22 (2). San José: Editorial de la Universidad de Costa Rica, 2009.

Soto Quirós, Ronald. "Desaparecidos de la nación: Los indígenas en la construcción de la identidad nacional costarricense 
1851-1942". Revista de Ciencias Sociales 82. San José: Editorial de la Universidad de Costa Rica, 1998.

Díaz Arias, David. "Una Fiesta del Discurso: vocabulario político e identidad nacional en el discurso de las celebraciones de la independencia en Costa Rica, 18481921". Revista Estudios 17. San José: Universidad de Costa Rica, Centro de Estudios Generales, 2003.

Viales Hurtado, Ronny. "El Museo Nacional de Costa Rica y los albores del discurso nacional costarricense". Vínculos 21 (1-2). San José: Museo Nacional de Costa Rica, 1995.

\section{REVISTAS ELECTRONICAS}

Molina, Iván. "La Costa Rica de 1921 y el discurso de Joaquín García Monge ante el Monumento Nacional". Revista Comunicación 17 (29). Tecnológico de Costa Rica, 2008: 74-76. En: http://www. tec.cr/sitios/Docencia/ciencias_lenguaje/ revista_comunicacion/Volumen $\% 20$
$17 \% 20$ a \% F 1 o \% $2029 \% 20 \mathrm{No} \% 20$ especial\%202008/pdf's/imolina.pdf [Consultado el 15 de marzo de 2013].

Molina, Iván. "Intelectuales y política en Costa Rica. El caso del discurso de Joaquín García Monge ante el Monumento Nacional (1921)". Memoria y Sociedad 13 (26). Colombia, 2009. En: http:// memoriaysociedad.javeriana.edu. co/anexo/articulo/doc/6ef_5_26.pdf [Consultado el 1 de marzo de 2013].

Díaz Arias, David. "Ritos escolares y símbolos nacionales en la fiesta de la independencia en Costa Rica, 18991921". Asociación para el Fomento de los Estudios Históricos en Centroamérica 19. 2006. En: http://ress.afehc.apinc. org/ articulos2/fichiers/portada_ afehc_ articulos17.pdf [Consultado el 16 de marzo de 2013].

Fecha de ingreso: 17/06/2011 Fecha de aprobación: 28/10/2011 
